Research Journal of Applied Sciences 5 (2): 131-136, 2010

ISSN: $1815-932 \mathrm{X}$

(C) Medwell Journals, 2010

\title{
Acceleration of Wound Healing Potential of Benzyl N'-(Indol-3-Ylmethylidene)- Hydrazinecarbodithioate Derivatives in Experimental Rats
}

\author{
${ }^{1}$ Fathi Farag Mughrabi, ${ }^{1}$ Harita Hashim, ${ }^{2}$ Mahmood Ameen, \\ ${ }^{3}$ Hamid Khaledi and ${ }^{3}$ Hapipah Mohd. Ali \\ ${ }^{1}$ Department of Biology, Faculty of Applied Science, \\ University of Teknologi, Mara 40450, Shah Alam, Malaysia \\ ${ }^{2}$ Department of Molecular Medicine, Faculty of Medicine, \\ University of Malaya, 50603, Kuala Lumpur, Malaysia \\ ${ }^{3}$ Department of Chemistry, Faculty of Science, \\ University of Malaya, 50603, Kuala Lumpur, Malaysia
}

\begin{abstract}
The effects of topical application of Benzyl N'-(indol-3-Ylmethylidene)-Hydrazinecarbodithioate derivatives $(\mathrm{BHC})$ on the process of wound healing enclosure and histology of healed wound were assessed. Five groups of adult male Sprague Dawley rats, all animals were experimentally wound in the posterior neck area. About $0.2 \mathrm{~mL}$ of $10 \%$ Tween 20 solution was applied to the wound of Group 1 animals (negative control). Intrasite gel was applied topically to wounds of Group 2 animals as reference. About $0.2 \mathrm{~mL}$ of 25, 50 and $100 \mathrm{mg} \mathrm{mL} \mathrm{m}^{-1}$ of compound derivative were applied to the wounds of Group 3,4 and 5, respectively. Macroscopically, wound dressed with compound derivative significantly healed earlier than those treated with $10 \%$ Tween 20 solution. Also wound dressed with $100 \mathrm{mg} \mathrm{mL}^{-1}$ compound derivative accelerate the rate of wound healing compared to those dressed with Intrasite and 25 and $50 \mathrm{mg} \mathrm{mL}^{-1}$ compound derivative. Histological analysis of healed wounds dresses with compound derivative showed comparatively less scar width at wound enclosure and healed wound contained less macrophages and large amount of collagen with angiogenesis compared to wounds dressed with $10 \%$ Tween 20 solution. In conclusion, wounds dressed with $100 \mathrm{mg} \mathrm{mL}^{-1}$ of compound derivative significantly enhanced the acceleration of the rate of wound healing enclosure and histologically healed wounds contain comparatively less macrophages and more collagen with angiogenesis.
\end{abstract}

Key words: Benzyl N'-(indol-3-ylmethylidene)-hydrazinecarbodithioate derivatives, wound healing, intrasite gel, histology, placebo, tween 20

\section{INTRODUCTION}

Indole derivatives constitute an important class of therapeutical agent in medicinal chemistry including antidepressive (Joshi and Chand, 1982), ant allergic (Unangst et al., 1989), antimicrobial (Canoira et al., 1989), antioxidant (Kaneko et al., 2000; Liu and Ng, 2000). On the other hand, antimicrobial (Tarafder et al., 2002), Anticancer (Ali et al., 2002), antibacterial and antifungal (Singh and Varshney, 2006) properties have been reported to be associated with the schiff bases derived from S-alkyl- or S-aryldithiocarbazate.

There are no data available regarding wound healing processing of this derivative compound in rats. Therefore, The present study was undertaken to evaluate the rate of wound healing properties of derivatives (BHC) in experimental rats. The current study revealed that wounds treated with derivatives $(\mathrm{BHC})$ as topical application of wounds significantly accelerate the wound healing process.

\section{MATERIALS AND METHODS}

Preparation of S-benzyldithiocarbazate: This compound was synthesized as reported previously (Tarafder and Ali, 1980). A mixture of hydrazine hydrate $(10 \mathrm{~g}, 0.2 \mathrm{moL})$ and potassium hydroxide $(11.4 \mathrm{~g}, 0.2 \mathrm{moL}$ ) in $90 \%$ ethanol $(70 \mathrm{~mL})$ was cooled in an ice bath. Carbon disulphide (15.2 g, $0.2 \mathrm{moL}$ ) was then added drop-wise with vigorous stirring. The temperature of the reaction mixture

Corresponding Author: Fathi Farag Mughrabi, U1-17-06 Ampang Damai Condo, Jln Wawasan 3/8A, Bandar Baru Ampang 68000, Selangor, Malaysia 
was not allowed to rise above $5^{\circ} \mathrm{C}$ during the period of addition of carbon disulfide. To the mixture, $40 \%$ ethanol $(60 \mathrm{~mL})$ was added and the solution was cooled in ice. Benzyl chloride ( $25.3 \mathrm{~g}, 0.2 \mathrm{moL}$ ) was then added slowly with vigorous stirring. The white product was separated by filtration, washed with water and dried in air. The crude product was recrystallized from absolute ethanol yield $23 \mathrm{~g}(58 \%)$.

Preparation of benzyl $N^{\prime}$-(indol-3-ylmethylidene)hydrazinecarbodithioate: The Schiff base was synthesized as reported previously (Khaledi et al., 2008). Indole-3-carbaldehyde (4.35 g, $0.03 \mathrm{moL})$ and $S$-benzyl dithiocarbazate $(5.94 \mathrm{~g}, 0.03 \mathrm{moL})$ were heated in methanol $(300 \mathrm{~mL})$ for $3 \mathrm{~h}$. The solution was set aside for few hours whereupon a yellow precipitate formed. This precipitate was filtered off, washed with cold ethanol and dried over silica gel yield, $8.3 \mathrm{~g} \mathrm{(85 \% )} \mathrm{(Fig.} \mathrm{1).}$

Intrasite gel: Intrasite gel was purchased from University Malaya Medicial center Pharmacy. Intrasite gel is a colorless transparent aqueous gel which contains a modified Carboxy Methyl Cellulose (CMC) polymer together with propylene glycol as a humectants and preservative. Intrasite gel is an amorphous hydrogel which gently re-hydrates necrotic tissue, facilitate autolytic debridemen while being able to loosen and absorb slough and exudates, cleaning the way for effective wound healing.

It is also designed for wounds that are granulating and epithelialising. It can also be used to provide the optimum moist wound management environment during the later stages of wound closure. It is non-adherent and does not harm viable tissue or the skin surrounding the wound. This makes Intrasite gel ideal for every stage in

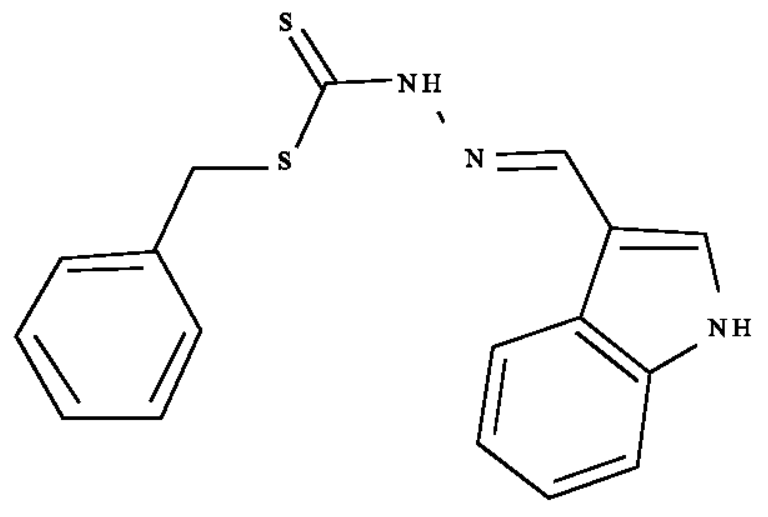

Fig. 1: Benzyl N'-(indol-3-ylmethylidene)-hydrazinecarbodithioate the wound management process. (Intrasite gel is a trademark for Smith and Nephew Ltd) (Williams, 1994).

Lignocaine HCl (2\%, $\left.100 \mathrm{mg} 5 \mathrm{~mL}^{-1}\right)$ : The local anesthesia was purchased from experimental animal house, Faculty of Medicine, University Malaya. About $1 \mathrm{~mL}$ of Lignocaine was injected subcutaneous.

Experimental animals: Sprague Dawley adult male rats were obtained from the experimental animal house, Faculty of Medicine, University of Malaya and Ethic No. PM/27/07/2009/MAA (R). The rats were divided randomly into 5 groups of 6 rats each. Each rat that weighted between 200-220 g was housed separately (one rat per cage). The animals were maintained on standard pellet diet and tap water. The study was approved by the ethics Committee for animal experimentation, Faculty of Medicine, University of Malaya, Malaysia. Throughout the experiments, all animals received human care according to the criteria outlined in the Guide for the Care and Use of laboratory Animals prepared by the National Academy of Sciences and published by the national Institute of health.

Experimentally induced wounds: The animals were anesthetized by diethyl ether. The skin shaved by electrical shaver, disinfected with $70 \%$ alcohol and injected with $1 \mathrm{~mL}$ of Lignocaine $\mathrm{HCl}\left(2 \%, 100 \mathrm{mg}^{2} \mathrm{~mL}^{-1}\right)$. An area of uniform wound $2.00 \mathrm{~cm}$ in diameter was excised from the nape of the dorsal neck of all rats with the aid of round seal as described by Morton and Malone (1972), (Fig. 2) with slight modification. Avoid incision of the muscle layer and tension of skin was kept constant during the procedure. The wound area was measured immediately

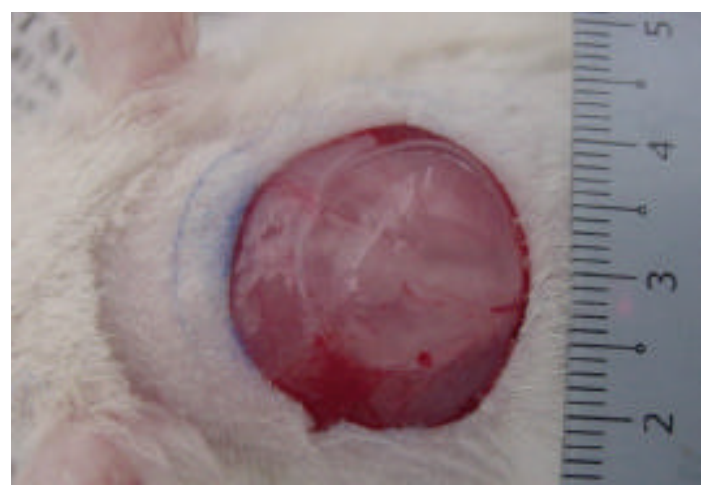

Fig. 2: About $2 \mathrm{~cm}$ diameter excision skin wound on day 0 before application of vehicle 
under light diethyl ether anesthesia as described by Nayak and Pinto Pereira (2006) with slight modification.

Topical application of vehicles: Wounds of Group 1 animals were dressed with $0.2 \mathrm{~mL}$ of $10 \%$ Tween 20 solution as a negative control twice daily. Wounds of Group 2 rats were dresses topically with Intrasite gel as a reference, twice daily. About $0.2 \mathrm{~mL}$ of 25,50 and $100 \mathrm{mg}$ $\mathrm{mL}^{-1}$ of compound derivative were applied topically twice daily to the wound of Group 3, 4 and 5 (experimental animals), respectively as described by Chah et al. (2006) with slight modification. The wound was observed daily until complete epithelization.

The wound closure rate was assessed by tracing the wound on days $1,5,10$ and 15 post-wounding using transparency papers and permanent marker as described by Nayak and Pinto Pereira (2006) with slight modification. The wound areas recorded were measured using a graph paper. Number of days required for falling of scar without any residual raw wound gave the period of epithelization. The percent wounds healing on these days are determined.

Histological evaluation of healed wounds: The skin specimen from wounds healed areas were fixed in 10\% buffered formalin and processed by paraffin tissue processing machine. The healed skin was assessed by taking a $5 \mu$ section stained with hematoxylin and eosin.

Statistical analysis: All values are reported as mean \pm SEM and the statistical significance of differences among groups were assessed using one-way ANOVA. A value of $\mathrm{p}<0.05$ was considered significant.

\section{RESULTS AND DISCUSSION}

Wounds dressed with compound derivative showed considerable signs of dermal healing and significantly $(p<0.05)$ healed earlier compared to wounds dressed with $10 \%$ Tween 20 (negative control) (Table 1, Fig. 3 and 4). Animals in the $100 \mathrm{mg} \mathrm{mL}^{-1}$ of compound derivative treated group showed significantly better healing and healed faster compared to animals in the 25 and $50 \mathrm{mg} \mathrm{mL}^{-1}$ compound-treated groups.

There were no significant differences between wounds dressed with 25 and $50 \mathrm{mg} \mathrm{mL}^{-1}$ of compound derivative in the term of duration of wound healing enclosure (Table 1). Histologically, wound dressed with compound derivative contained comparably less scar at wound enclosure and healed wound contained few macrophages and more collagen and proliferating
Table 1: Time required for wound healing by compound derivative in experimental animals

\begin{tabular}{|c|c|c|c|}
\hline $\begin{array}{l}\text { Animal } \\
\text { groups }\end{array}$ & $\begin{array}{l}\text { No. of } \\
\text { animals }\end{array}$ & Type of dressings & $\begin{array}{c}\text { Healing time } \\
\text { (days) }\end{array}$ \\
\hline 1 & 6 & $\begin{array}{l}10 \% \text { Tween } 20 \\
\text { (negative control) }\end{array}$ & $19.92 \pm 0.55^{\mathrm{a}}$ \\
\hline 2 & 6 & $\begin{array}{l}\text { Intrasite gel } \\
\text { (positive control) }\end{array}$ & $14.81 \pm 0.37^{b}$ \\
\hline 3 & 6 & $\begin{array}{l}25 \mathrm{mg} \mathrm{kg}^{-1} \\
\text { compound derivative }\end{array}$ & $14.67 \pm 0.37^{b}$ \\
\hline 4 & 6 & $\begin{array}{l}50 \mathrm{mg} \mathrm{kg}^{-1} \\
\text { compound derivative }\end{array}$ & $14.50 \pm 0.18^{b}$ \\
\hline 5 & 6 & $\begin{array}{l}100 \mathrm{mg} \mathrm{kg}^{-1} \\
\text { compound derivative }\end{array}$ & $11.83 \pm 0.36^{c}$ \\
\hline
\end{tabular}

All values were expressed as mean and \pm standard error mean. Mean with different superscripts were significantly different $(p<0.05)$

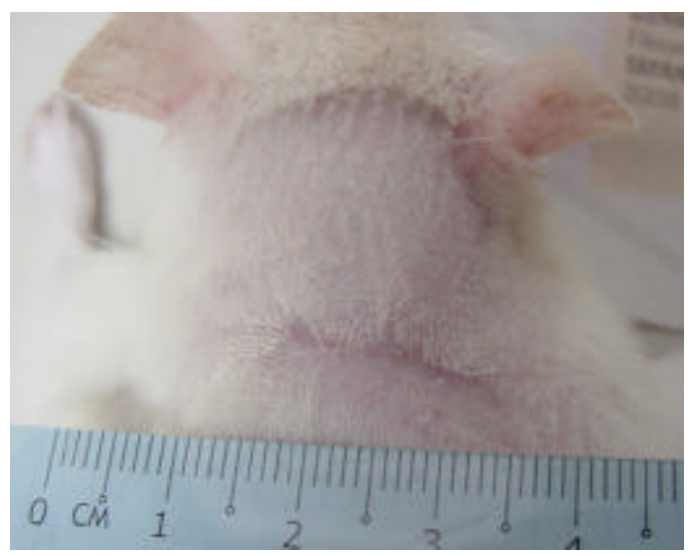

Fig. 3: Complete wound healing on day 12 with $0.2 \mathrm{~mL}$ of $100 \mathrm{mg} \mathrm{kg}^{-1}$ compound derivative on day 12

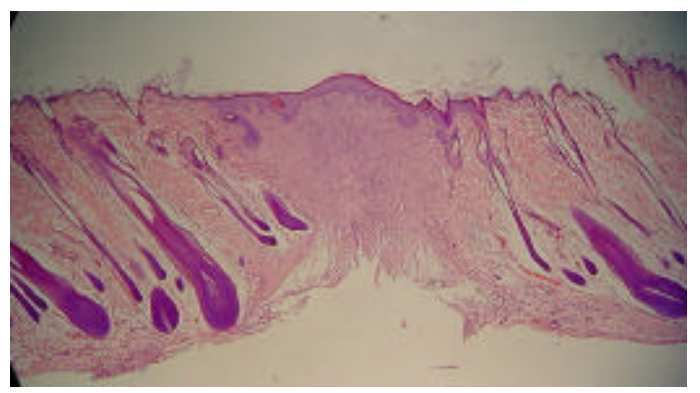

Fig. 4: Histological section of healed wound dressed with $0.2 \mathrm{~mL}$ of $100 \mathrm{mg} \mathrm{kg}^{-1}$ compound derivative showng comparatively narrow scar at the wound closure $(\mathrm{H}$ and $\mathrm{E}$ stain $\times 4)$

blood capillaries compared with wound dressed with $10 \%$ Tween 20 solution (Fig. 5-8). In the present study, topical application of compound derivative significantly enhanced the rate of wound healing and histologically, healed wound contain less macrophages, more collagen and angiogenesis. Wound healing effects may be due to up-regulation of collagen expression (Bonte et al., 1993) 


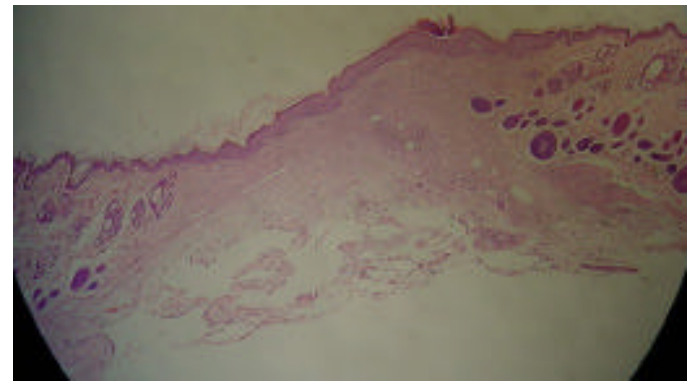

Fig. 5: Histological section of healed wound dressed with $0.2 \mathrm{~mL}$ of Tween 80 (negative control) showing comparatively wide scar at the wound closure $(\mathrm{H}$ and $\mathrm{E}$ stain $\times 4)$

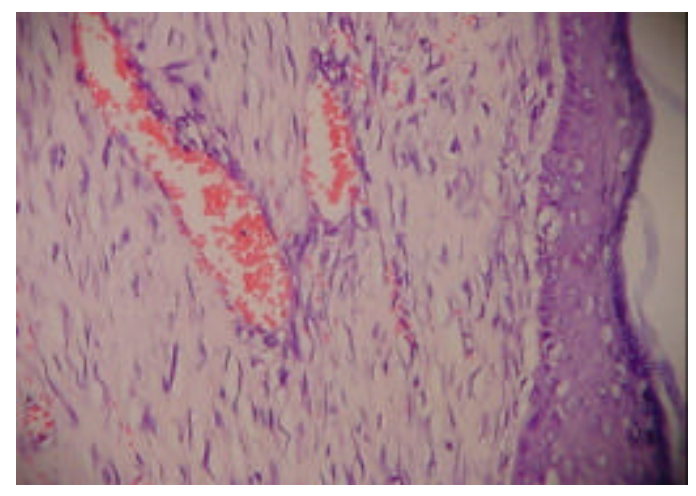

Fig. 6: Histological section of healed wound dressed with $0.2 \mathrm{~mL}$ of $100 \mathrm{mg} \mathrm{k}^{-1}$ compound derivative. Granulation tissue contains comparatively more collagen, fibroblast and bloog capillaries and few or absence of inflammatory cells (macrophages) ( $\mathrm{H}$ and $\mathrm{E}$ stain $\times 4$ )

and an increase in tensile strength of the wounds (Suguna et al., 1996). Similarly, enhanced healing activity has been attributed to increased collagen formation and angiogenesis (Trabucchi et al., 1986; Shukla et al., 1999).

Collagen played a central role in the healing of wounds and it is a principal component of connective tissue and provides a structural framework for the regenerating tissue (Cohen et al., 1992). Angiogenesis in granulation tissues improves circulation to the wound site thus providing oxygen and nutrients essential for the healing process (Szabo et al., 1995) that include reepithelization.

Stimulate epithelial cell proliferation and angiogenesis are important for wound healing process (Buntrock et al., 1982). With the consistence of the present study, Habibipour et al. (2003) showed

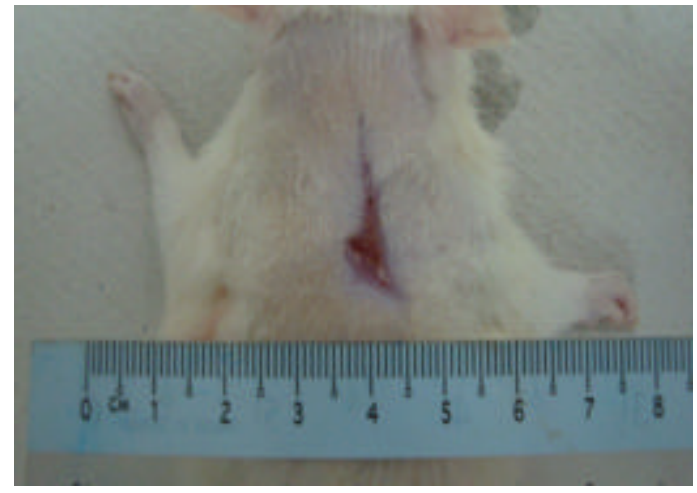

Fig. 7: Incomplete wound healing on day 17 in animal treated with $0.2 \mathrm{~mL}$ of $10 \%$ Tween 80 (negative control)

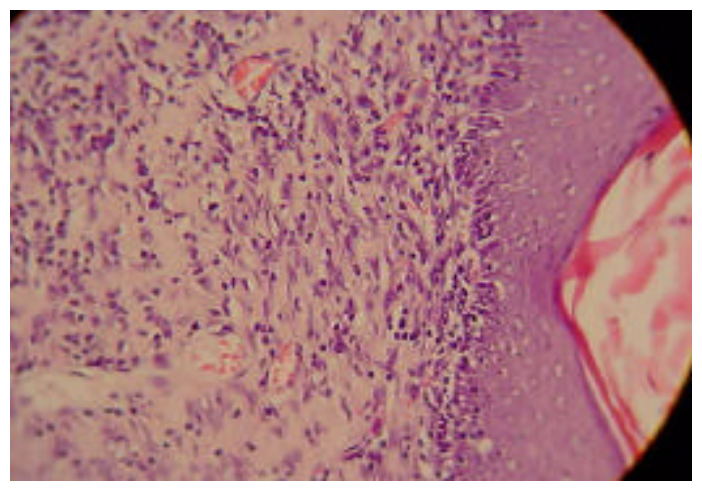

Fig. 8: Histological section of healed wound dressed with $10 \%$ Tween 20 (negative control). Granulation tissue contains less collagen, fibroblast and blood capillaries and more inflammatory cells (macrophages) ( $\mathrm{H}$ and $\mathrm{E}$ stain $\times 40$ )

that histological analysis of the treated healed wound group contained a large amount of fibroblast proliferation, collagen synthesis and neovascularization which resulted in an increased wound tensile strength and accelerated healing wound. Wound healing mechanisms may be contributed to stimulate the production of antioxidants in wound site and provides a favorable environment for tissue healing (Shukla et al., 1999).

Compound derivative have shown antioxidant activity (Kaneko et al., 2000; Liu and Ng, 2000). Antioxidants have been reported to play a significant role in the wound healing process. It appears that antioxidant may be an important contributory factor in the wound healing property (Shukla et al., 1999). Topical applications of compounds with antioxidant properties significantly improve wound healing and protect tissues from oxidative damage (Martin, 1996). 


\section{CONCLUSION}

In conclusion, the current study revealed that the dressed with compound derivative, as topical application of wounds enhanced significantly wound healing process.

\section{ACKNOWLEDGEMENTS}

The researchers would like to express their gratitudes to the staff of the Faculty of Medicine Animal House for the care and supply of rats. The researchers would also like to acknowledge the Universiti Teknologi MARA for financial support under the DANA (600-RMI/ST/DANA 5/3/Dst (289/2009) and FRGS(600-RMI/ST/FRGS 5/3/ Fst (34/2010) grants. In addition the authors would also like to thank the University of Malaya for its contribution to this research.

\section{REFERENCES}

Ali, M.A., A.H. Mirzaa, R.J. Butcherb, M.T.H. Tarafder, T.B. Keat and A.M. Ali, 2002. Biological activity of palladium (II) and platinum (II) complexes of the acetone Schiff bases of S-methyl- and Sbenzyldithiocarbazate and the X-ray crystal structure of the [Pd(asme)2] (asme=anionic form of the acetone Schiff base of S-methyldithiocarbazate) complex. J. Inorganic Biochem., 92: 141-148.

Bonte, F., M. Dumas, C. Chaudagne and A. Meybeck, 1993. Influence of asiatic acid, madecassic acid and asiaticoside on human collagen I synthesis. Planta Med., 60: 133-135.

Buntrock, P., K.D. Jentzsch and G. Heder, 1982. Stimulation of wound healing. Using brain extract with fibroblast growth factor activity. II. Histological and morphometric examination of cells and capillaries. Exp. Pathol., 21: 62-67.

Canoira, L., J.G. Rodriguez, J.B. Subirats, J.A. Escario, I. Jimenez and A.R. Martinez-Fernandez, 1989. Synthesis, structure and anti-fungal activity of 3(2'-nitrovinyl)indoles. Eur. J. Med. Chem., 24: 39-42.

Chah, K.F., C.A. Eze, C.E. Emuelosi and C.O. Esimone, 2006. Antibacterial and wound healing properties of methanolic extracts of some Nigerian medicinal plants. J. Ethnopharmacol., 104: 164-167.

Cohen, I.K., R.F. Diegelmann and W.J. Lindblad, 1992. Wound Healing: Biochemical and Clinical Aspects. WB Saunders Co., Philadelphia, USA., ISBN: 0721625649 .
Habibipour, S., T.M. Oswald, F. Zhang, P. Joshi, X.C. Zhou, W. Dorsett-Martin and W.C. Lineaweaver, 2003. Effect of sodium diphenylhydantion on skin wound healing in rats. Plastic Reconstructive Surgery, 112: 1620-1627.

Joshi, K.C. and P. Chand, 1982. Indole derivatives biologically active. Pharmazie, 37: 1-12.

Kaneko, S., K. Okumura, Y. Numaguchi, H. Matsui and K. Murase et al., 2000. Melatonin scavenges hydroxyl radical and protects isolated rat hearts from ischemic reperfusion injury. Life Sci., 67: 101-112.

Khaledi, H., H.M. Ali and S.W. Ng, 2008. Benzyl $\mathrm{N}^{\prime}$-(1H-indol-3-ylmethylidene)-hydrazinecarbodithioate. Acta Crystallographica, 64: 2107-2107.

Liu, F. and T.B. Ng, 2000. Effect of pineal indoles on activities of the antioxidant defense enzymes superoxide dismutase, catalase and glutathione reductase and levels of reduced and oxidized glutathione in rat tissues. Biochem. Cell Biol., 78: 447-453.

Martin, A., 1996. The use of antioxidants in wound healing. Dermatol. Surg., 22: 156-160.

Morton, J.J.P. and M.H. Malone, 1972. Evaluation of vulnerary activity by an open wound procedure in rats. Arch. Int. Pharmacodyn, 196: 117-126.

Nayak, B.S. and L.M. Pinto Pereira, 2006. Catharanthus roseus flower extract has wound-healing activity in Sprague Dawley rats. Br. Med. Central Complement. Alternat. Med., 6: 41-41.

Shukla, A., A.M. Rasik and B.N. Dhawan, 1999. Asiaticoside-induced elevation of antioxidant levels in healing wounds. Phytother. Res., 13: 50-54.

Singh, H.L. and A.K. Varshney, 2006. Synthetic, structural and biochemical studies of organotin(IV) with Schiff bases having nitrogen and sulphur donor ligands. Bioinorganic Chem. Appl., 2006: 23245-23245.

Suguna, L., P. Sivakumar and G. Chandrakasan, 1996. Effect of centella asiatica extract on dermal wound healing in rats. India J. Exp. Bol., 34: 1208-1211.

Szabo, S., S. Kusstatscher, G. Sakoulas, Z. Sandor, A. Vincze and M. Jadus, 1995. Growth factors: New endogeneous drug for ulcer healing. Scandinavian J. Gastroenterol., 210: 15-18.

Tarafder, M.T.H. and M.A. Ali, 1980. Metal complexes of some schiff bases derived from sbenzyldithiocarbazate. Can. J. Chem., 58: 727-727. 
Tarafder, M.T.H., K.B. Chew, K.A. Crouse, A.M. Ali, B.M. Yamin and H.K. Fun, 2002. Synthesis and characterization of $\mathrm{Cu}(\mathrm{II}), \mathrm{Ni}(\mathrm{II})$ and $\mathrm{Zn}$ (II) metal complexes of bidentate NS isomeric Schiff bases derived from S-methyldithiocarbazate (SMDTC): Bioactivity of the bidentate NS isomeric Schiff bases, some of their $\mathrm{Cu}(\mathrm{II}), \mathrm{Ni}(\mathrm{II})$ and $\mathrm{Zn}$ (II) complexes and the X-ray structure of the bis[Smethyl-beta- $\mathrm{N}$-(2-furylmethyl) methylenedithiocarbazato]zinc(II) complex. Polyhedron, 21: 2683-2690.
Trabucchi, E., F. Preis-Baruffaldi, C. Baratti and W. Montorsi, 1986. Topical treatment of experimental skin lesions in rats: macroscopic, microscopic and scanning electron-microscopic evaluation of the healing process. Int. J. Tissue Reaction, 8: 533-544.

Unangst, P.C., D.T. Connor, S.R. Stabler, R.J. Weikert and M.E. Carethers et al., 1989. Novel indolecarboxamidotetrazoles as potential antiallergy agents. J. Med. Chem., 32: 1360-1366.

Williams, C., 1994. Intrasite Gel: A hydrogel dressing. Br. J. Nurs., 3: 843-846. 